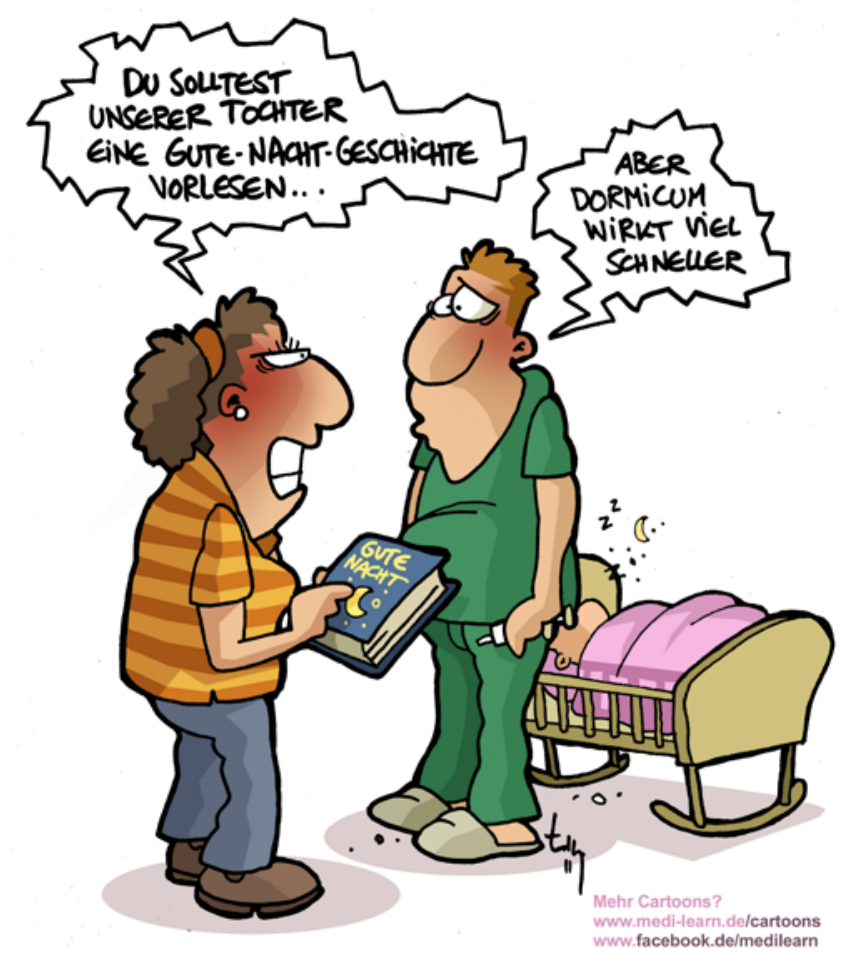

„Wenn wir jetzt anfangen, uns noch entschuldigen zu müssen dafür, dass wir in Notsituationen ein freundliches Gesicht zeigen, dann ist das nicht mein Land."

Bundeskanzlerin Angela Merkel

\title{
Angebohrt
}

\section{Vogel mit Gebiss}

Wenn einer in Deutschland Mut zur Lücke hat, dann ist das Schauspieler Jürgen Vogel. Was wurde nicht schon alles über seine fehlenden Beißerchen, die spitzen Eckzähne und sein Lächeln geschrieben. Für die einen supersexy, für die anderen ein völliges No-Go. Vogel trägt die Zahndiskussion mit Fassung und Humor - und ändert gar nichts an seinem Markenzeichen. Jacketkronen, Implantate, Zahnspange - alles nichts für den Hamburger Jung' (mit Wahlheimat Berlin), der seit jeher zur Mangelerscheinung in seinem Oberkiefer steht. Nun aber wird sich der 47-Jährige einer Verwandlung unterziehen: Für die Neuverfilmung von „Winnetou" muss sich der Schauspieler die Zähne sozusagen zwangsweise richten lassen. Keine Sorge allerdings: Niemand muss fürchten, den alten spitzzahnigen Vogel nicht mehr wiederzusehen. Die Kauleiste für die Winnetou-Verfilmung ist ein Fake - die Dritten über den Zweiten sozusagen. Dass Jürgen Vogel Gefallen dran finden könnte, steht wohl kaum zu befürchten: Die falschen Zähne könnten ein intensives Bleaching gut gebrauchen und sind auch ansonsten - wie sich's für den Wilden Westen gehört - nicht gerade das, was man heutzutage unter einem Hollywood-Gebiss versteht. Zu sehen sind sie zu Weihnachten im Fernsehen.

\section{Halbgott mit Nasenring}

Es ist aber auch wirklich ein Kreuz mit dem Image: Ein Rockmusiker im Polohemd? Die Sekretärin in Lederhosen? Der Zahnarzt im Hawaiihemd? Geht alles gar nicht. Sind die Bilder wirklich so fest in den Köpfen verhaftet, dass man die Kleidung ganz eng mit Kompetenz verknüpft? Die eindeutige Antwort: Ja. Das sagen zumindest australische Wissenschaftler, die untersucht haben, wie sich das äußere Erscheinungsbild von Klinikärzten auf das Vertrauen ihrer Patienten auswirkt. In mehreren Schritten veränderten die Ärzte innerhalb von sieben Monaten ihre Kleidungsstücke. Von "ganz in Weiß $\beta^{\text {“ }}$ - wie es die Patienten gewohnt waren - zu „bunt und wild“. Die ehemaligen "Halbgötter in Weiß" verwandelten sich also stufenweise in eine Mischung zwischen Hippie und Rocker - bis hin zu Hawaiihemd und Nasenring. Parallel dazu wurden rund 1700 Patienten befragt, wie es um ihr Vertrauen zum jeweiligen Arzt steht. Das wenig überraschende Ergebnis: Je lässiger die Kleidung des Arztes wurde, umso mehr schwand das Vertrauen. Das Tragen eines Nasenrings untergrub das Image des Arztes vollends. Was lernen wir daraus? Kittel und Krawatte schaffen Kompetenz. Man hätte es sich denken können: Fortbildung, Wissen, Erfahrung - alles völlig überbewertet. 